\title{
Draft Genome Resource for the Potato Powdery Scab Pathogen Spongospora subterranea
}

\author{
Stefan Ciaghi, ${ }^{1}$ Sigrid Neuhauser, ${ }^{1}$ and Arne Schwelm ${ }^{2, \dagger}$ \\ ${ }^{1}$ University of Innsbruck, Institute of Microbiology, Technikerstraße 25, 6020 Innsbruck, Austria \\ ${ }^{2}$ Swedish University of Agricultural Sciences, Department of Plant Biology, Uppsala BioCenter, Linnean \\ Centre for Plant Biology, P.O. Box 7080, SE-75007 Uppsala, Sweden
}

\begin{abstract}
The Plasmodiophorida (Phytomyxea, Rhizaria) are a group of protists that infect plants. Of this group, Spongospora subterranea causes major problems for the potato industry by causing powdery scab and root galling of potatoes and as vector for the Potato mop-top virus (PMTV) (genus Pomovirus, family Virgaviridae). A single tuber isolate (SSUBK13) of this uncultivable protist was used to generate DNA for lllumina sequencing. The data were assembled to a draft genome of $28.08 \mathrm{Mb}$ consisting of 2,340 contigs and an $L 50$ of 280 . A total of 10,778 genes were predicted and $93 \%$ of the BUSCO genes were detected. The presented genome assembly is only the second genome of a plasmodiophorid. The data will accelerate functional genomics to study poorly understood interaction of plasmodiophorids and their hosts.
\end{abstract}

\section{Genome Announcement}

Spongospora subterranea belongs to the Plasmodiophorida (Phytomyxea, Rhizaria) (Neuhauser et al. 2014; Sierra et al. 2016). This soilborne, obligate biotrophic protist is present in most potato-growing regions worldwide (Gau et al. 2013). It causes powdery scab of potato tubers, root galling in its host, reduces tuber yield, and transmits the Potato mop-top virus (PMTV) (genus Pomovirus, family Virgaviridae) (Balendres et al. 2016; Falloon et al. 2016). It can also diminish the growth of other solanaceous crops, such as tomatoes (Solanum lycopersicum) (Balendres et al. 2018). Because of their intracellular growth and obligate host-dependent life style, genomic data for plasmodiophorids are rare, although those pathogens cause substantial crop damage, e.g., in brassicas, sugar beet, or gramineous crops (Schwelm et al. 2018). So far, the only publicly available whole-genome data of plasmodiophorids are from the clubroot pathogen Plasmodiophora brassicae (Bi et al. 2016; Schwelm et al. 2015). Therefore, the here-presented S. subterranea data now enables comparative analyses between plasmodiophorid plant pathogens.

The genome data described here were generated from DNA of purified sporosori (characteristic aggregates of haploid resting spores) from potatoes originating from Lower Saxony, Germany (IB2016400). Sporosori from an individual potato tuber were collected to generate a single tuber isolate (SSUBK13). To reduce the amount of bacterial contamination, sporosori were immersed in lysis solution (GeneJET plasmid miniprep kit; ThermoScientific) for $5 \mathrm{~min}$ before washing twice by centrifugation in sterile water. Sporosori were purified by sequential filtering using CellTrics strainers (Sysmex). Material between 20 and $50 \mu \mathrm{m}$ was collected and a subsample of the sporosori was visually checked for the presence of fungal and bacterial contamination prior DNA extraction. Sporosori were snap-frozen in

\footnotetext{
${ }^{\dagger}$ Corresponding author: Arne Schwelm; E-mail: arne.schwelm@slu.se
}

Accepted for publication 30 June 2018.
Funding

This work and Arne Schwelm were supported by FORMAS Swedish Research Council (grant 2015-1317). Stefan Ciaghi and Sigrid Neuhauser were funded by the Austrian Science Fund (grant Y0810-B16). 
liquid nitrogen and disrupted using a Fastprep $245 \mathrm{G}$ homogenizer (MP Biomedicals, LLC). For lysis, the material was incubated in cetyltrimethylammonium bromide buffer at $65^{\circ} \mathrm{C}$ for 10 to $12 \mathrm{~h}$ before iso-amylacohol and chloroform extraction and isopropanol precipitation of the DNA. A yellow-brown pigment coprecipitated with the DNA was separated from the DNA via gel electrophoresis. The genomic DNA of a size larger than $10 \mathrm{~kb}$ was purified from the gel using the ZYMO large-fragment DNA gel purification kit (Zymo Research Corporation). A strand-specific paired-end library ( $2 \times 150 \mathrm{bp})$ was constructed and was sequenced using HiSeq 2500 technique (Illumina) at the Vienna Biocenter Core Facilities sequencing platform. Reads were quality checked using FastQC and sequencing adapters, and low-quality reads (sliding window $5 \mathrm{bp}$; average quality score <20) were removed using Trimmomatic v0.36 (Bolger et al. 2014). Only surviving read pairs in which each read was longer than 70 bp were processed further. To filter out reads from contaminating organisms (e.g., bacteria) and the host, reads that matched to the potato genome (Potato Genome Sequencing Consortium et al. 2011) or the National Center for Biotechnology Information (NCBI) bacterial reference database using Bowtie2 v2.2.6 (Langmead and Salzberg 2012) were removed. The so-filtered reads were assembled using Velvet v1.2.10 (Zerbino and Birney 2008) and SPAdes v3.11.1 (Bankevich et al. 2012). Velvet assembled ( $k$ mer set to 31 ) contigs ( $\geq 1,000 \mathrm{nt}$, coverage $\geq 13$ ) were used in the SPAdes assembly (kmer settings $23,33,41,55,63$ ) as untrusted contigs. From this assembly only contigs longer than $500 \mathrm{bp}$ were used and were manually sorted based on coverage, blast $\mathrm{N}$ hit, and length. Contigs with coverage above 30 were selected when their BlastN hit did not exclusively match bacterial genomes or the potato genome. All other contigs were analyzed by BlastX, using the NCBI nr database and $S$. subterranea protein models (Schwelm et al. 2015) and contigs with their best hits matching only to $P$. brassicae or S. subterranea protein models were also kept. Gapfiller v1.10 (Boetzer and Pirovano 2012) and SSPACE-standard v3.0 (Boetzer et al. 2011) were used to improve scaffolding.

The $S$. subterranea SSUBK13 genome draft presented here consists of 2,340 scaffolds with a total length of $28.08 \mathrm{Mb}(229 \mathrm{~N} / 100 \mathrm{kbp})$ and 1,150 scaffolds above $5 \mathrm{~kb}$. The largest scaffold was 262,481 nt long (N50 value of 28,677; L50 value of 280). The GC content of $45.7 \%$ is lower than the $58 \%$ for $P$. brassicae (Schwelm et al. 2015) but comparable to the $46 \% \mathrm{GC}$ content of the genome of the rhizarian Bigellowiella natans (Curtis et al. 2012). After repeat-masking (RepeatMasker program), a total of 10,778 genes were predicted using the BRAKER1 v2.0 pipeline (Hoff et al. 2016), a TopHat v2.1.0 (Kim et al. 2013)-created BAM-file, and available RNAseq reads (Schwelm et al. 2015; European Nucleotide Archive [ENA] BioProject PRJEB9159). The completeness of the genome assembly was estimated using BUSCO v2.0.1 (Simão et al. 2015), identifying 93\% (88\% complete, 5\% partial) of the Eukaryota set. For $P$. brassicae, the only other sequenced Phytomyxea to date, $97 \%(94 \%$ complete, $3 \%$ partial) of BUSCO proteins are present in the isolate e3 (Schwelm et al. 2015). The presented genome draft contains the complete ribosomal DNA sequence (scaffold 678). The mitochondrial sequence was partially assembled from the unfiltered reads using MITObim (Hahn et al. 2013). Of the 10,780 predicted genes 1,991 could be categorized by KAAS (Moriya et al. 2007) to a KEGG category and 4,402 by eggNOG (Huerta-Cepas et al. 2016) to a $\mathrm{COG}$ (clusters of orthologous groups) category other than $\mathrm{S}$, which is unknown function. SingalP v4.1 (Petersen et al. 2011) predicted 697 secreted proteins, of which 102 were classified as potential effectors by the fungal effector predictor EffectorP 2.0 (Sperschneider et al. 2018). Using dbCAN (Yin et al. 2012), 300 carbohydrate active enzymes (CAZymes) were predicted $\left(\mathrm{e}\right.$ value $\left.<\mathrm{e}^{-05}\right)$.

Table 1. Metrics of the Spongospora subterranea SSUBK13 genome draft

\begin{tabular}{ll} 
Feature & \multicolumn{1}{c}{ Numbers } \\
Assembled genome size & $28,084,886 \mathrm{nt}$ \\
Number of scaffolds $(>1 \mathrm{~kb})$ & $2,340(2,255)$ \\
$\mathrm{N} 50$ & 28,677 \\
L50 & 280 \\
Largest scaffold & $262,481 \mathrm{nt}$ \\
Scaffolds $>25 \mathrm{~kb}$ & 339 \\
BUSCOs & $93 \%(271$ complete, 15 partial $)$ \\
Number of predicted genes & 10,780 \\
Number of predicted CAZymes & 300 \\
Number of predicted secreted proteins & 697 \\
\hline
\end{tabular}


The whole-genome sequence assembly (accessions OUQQ01000001 to OUQQ01002340) and the complete data set used in this report, including the lllumina raw reads have been deposited at the European Nucleotide Archive (ENA) under BioProject PRJEB26377 (Table 1).

\section{Acknowledgments}

Library preparation and Illumina Sequencing was performed at the Vienna Biocenter Core Facilities Next Generation Sequencing Unit.

\section{Literature Cited}

Balendres, M. A., Tegg, R. S., Amponsah, J., and Wilson, C. R. 2018. Zoosporangial root infection of tomato by Spongospora subterranea in hydroponic and glasshouse culture results in diminished plant growth. J. Phytopath. 166:412-419.

Balendres, M. A., Tegg, R. S., and Wilson, C. R. 2016. Key events in pathogenesis of Spongospora diseases in potato: A review. Australas. Plant Pathol. 45:229-240.

Bankevich, A., Nurk, S., Antipov, D., Gurevich, A. A., Dvorkin, M., Kulikov, A. S., Lesin, V. M., Nikolenko, S. I., Pham, S., Prjibelski, A. D., Pyshkin, A. V., Sirotkin, A. V., Vyahhi, N., Tesler, G., Alekseyev, M. A., and Pevzner, P. A. 2012. SPAdes: A new genome assembly algorithm and its applications to single-cell sequencing. J. Comput. Biol. 19:455-477.

Bi, K., He, Z., Gao, Z., Zhao, Y., Fu, Y., Cheng, J., Xie, J., Jiang, D., and Chen, T. 2016. Integrated omics study of lipid droplets from Plasmodiophora brassicae. Sci. Rep. 6:36965.

Boetzer, M., Henkel, C. V., Jansen, H. J., Butler, D., and Pirovano, W. 2011. Scaffolding pre-assembled contigs using SSPACE. Bioinformatics 27:578-579.

Boetzer, M., and Pirovano, W. 2012. Toward almost closed genomes with GapFiller. Genome Biol. 13:R56.

Bolger, A. M., Lohse, M., and Usadel, B. 2014. Trimmomatic: A flexible trimmer for Illumina sequence data. Bioinformatics 30:2114-2120.

Curtis, B. A., Tanifuji, G., Burki, F., Gruber, A., Irimia, M., Maruyama, S., Arias, M. C., Ball, S. G., Gile, G. H., Hirakawa, Y., Hopkins, J. F., Kuo, A., Rensing, S. A., Schmutz, J., Symeonidi, A., Elias, M., Eveleigh, R. J. M., Herman, E. K., Klute, M. J., Nakayama, T., Oborník, M., Reyes-Prieto, A., Armbrust, E. V., Aves, S. J., Beiko, R. G., Coutinho, P., Dacks, J. B., Durnford, D. G., Fast, N. M., Green, B. R., Grisdale, C. J., Hempel, F., Henrissat, B., Höppner, M. P., Ishida, K., Kim, E., Kořený, L., Kroth, P. G., Liu, Y., Malik, S. B., Maier, U. G., McRose, D., Mock, T., Neilson, J. A. D., Onodera, N. T., Poole, A. M., Pritham, E. J., Richards, T. A., Rocap, G., Roy, S. W., Sarai, C., Schaack, S., Shirato, S., Slamovits, C. H., Spencer, D. F., Suzuki, S., Worden, A. Z., Zauner, S., Barry, K., Bell, C., Bharti, A. K., Crow, J. A., Grimwood, J., Kramer, R., Lindquist, E., Lucas, S., Salamov, A., McFadden, G. I., Lane, C. E., Keeling, P. J., Gray, M. W., Grigoriev, I. V., and Archibald, J. M. 2012. Algal genomes reveal evolutionary mosaicism and the fate of nucleomorphs. Nature 492:59-65.

Falloon, R. E., Merz, U., Butler, R. C., Curtin, D., Lister, R. A., and Thomas, S. M. 2016. Root infection of potato by Spongospora subterranea: Knowledge review and evidence for decreased plant productivity. Plant Pathol. 65:422-434.

Gau, R. D., Merz, U., Falloon, R. E., and Brunner, P. C. 2013. Global genetics and invasion history of the potato powdery scab pathogen, Spongospora subterranea f.sp. subterranea. PLoS One 8:e67944.

Hahn, C., Bachmann, L., and Chevreux, B. 2013. Reconstructing mitochondrial genomes directly from genomic next-generation sequencing reads-A baiting and iterative mapping approach. Nucleic Acids Res. 41:e129.

Hoff, K. J., Lange, S., Lomsadze, A., Borodovsky, M., and Stanke, M. 2016. BRAKER1: Unsupervised RNA-Seq-based genome annotation with GeneMarkET and AUGUSTUS. Bioinformatics 32:767-769.

Huerta-Cepas, J., Szklarczyk, D., Forslund, K., Cook, H., Heller, D., Walter, M. C., Rattei, T., Mende, D. R., Sunagawa, S., Kuhn, M., Jensen, L. J., von Mering, C., and Bork, P. 2016. eggNOG 4.5: A hierarchical orthology framework with improved functional annotations for eukaryotic, prokaryotic and viral sequences. Nucleic Acids Res. 44 (D1):::D286-D293.

Kim, D., Pertea, G., Trapnell, C., Pimentel, H., Kelley, R., and Salzberg, S. L. 2013. TopHat2: Accurate alignment of transcriptomes in the presence of insertions, deletions and gene fusions. Genome Biol. 14:R36.
Langmead, B., and Salzberg, S. L. 2012. Fast gapped-read alignment with Bowtie 2. Nat. Methods 9:357-359.

Moriya, Y., Itoh, M., Okuda, S., Yoshizawa, A. C., and Kanehisa, M. 2007. KAAS: An automatic genome annotation and pathway reconstruction server. Nucleic Acids Res. 35:W182-W!85.

Neuhauser, S., Kirchmair, M., Bulman, S., and Bass, D. 2014. Cross-kingdom host shifts of phytomyxid parasites. BMC Evol. Biol. 14:33.

Petersen, T. N., Brunak, S., von Heijne, G., and Nielsen, H. 2011. SignalP 4.0: Discriminating signal peptides from transmembrane regions. Nat. Methods 8 : 785-786.

Potato Genome Sequencing Consortium, Xu, X., Pan, S., Cheng, S., Zhang, B., Mu, D., Ni, P., Zhang, G., Yang, S., Li, R., Wang, J., Orjeda, G., Guzman, F., Torres, M., Lozano, R., Ponce, O., Martinez, D., De la Cruz, G., Chakrabarti, S. K., Patil, V. U., Skryabin, K. G., Kuznetsov, B. B., Ravin, N. V., Kolganova, T. V., Beletsky, A. V., Mardanov, A. V., Di Genova, A., Bolser, D. M., Martin, D. M., Li, G., Yang, Y., Kuang, H., Hu, Q., Xiong, X., Bishop, G. J., Sagredo, B., Mejía, N., Zagorski, W., Gromadka, R., Gawor, J., Szczesny, P., Huang, S., Zhang, Z., Liang, C., He, J., Li, Y., He, Y., Xu, J., Zhang, Y., Xie, B., Du, Y., Qu, D., Bonierbale, M., Ghislain, M., Herrera, M. R., Giuliano, G., Pietrella, M., Perrotta, G., Facella, P., O'Brien, K., Feingold, S. E., Barreiro, L. E., Massa, G. A., Diambra, L., Whitty, B. R., Vaillancourt, B., Lin, H., Massa, A. N., Geoffroy, M., Lundback, S., DellaPenna, D., Buell, C. R., Sharma, S. K., Marshall, D. F., Waugh, R., Bryan, G. J., Destefanis, M., Nagy, I., Milbourne, D., Thomson, S. J., Fiers, M., Jacobs, J. M., Nielsen, K. L., Sønderkær, M., lovene, M., Torres, G. A., Jiang, J., Veilleux, R. E., Bachem, C. W., de Boer, J., Borm, T., Kloosterman, B., van Eck, H., Datema, E., Hekkert, B., Goverse, A., van Ham, R. C., Visser, R. G., and Visser, R. G.;. 2011. Genome sequence and analysis of the tuber crop potato. Nature 475:189-195.

Schwelm, A., Badstöber, J., Bulman, S., Desoignies, N., Etemadi, M., Falloon, R. E., Gachon, C. M. M., Legreve, A., Lukeš, J., Merz, U., Nenarokova, A., Strittmatter, M., Sullivan, B. K., and Neuhauser, S. 2018. Not in your usual Top 10: Protists that infect plants and algae. Mol. Plant Pathol. 19:1029-1044.

Schwelm, A., Fogelqvist, J., Knaust, A., Jülke, S., Lilja, T., Bonilla-Rosso, G., Karlsson, M., Shevchenko, A., Dhandapani, V., Choi, S. R., Kim, H. G., Park, J. Y., Lim, Y. P., Ludwig-Müller, J., and Dixelius, C. 2015. The Plasmodiophora brassicae genome reveals insights in its life cycle and ancestry of chitin synthases. Sci. Rep. 5:11153.

Sierra, R., Cañas-Duarte, S. J., Burki, F., Schwelm, A., Fogelqvist, J., Dixelius, C., González-García, L. N., Gile, G. H., Slamovits, C. H., Klopp, C., Restrepo, S., Arzul, I., and Pawlowski, J. 2016. Evolutionary origins of rhizarian parasites. Mol. Biol. Evol. 33:980-983.

Simão, F. A., Waterhouse, R. M., loannidis, P., Kriventseva, E. V., and Zdobnov, E. M. 2015. BUSCO: Assessing genome assembly and annotation completeness with single-copy orthologs. Bioinformatics 31:3210-3212.

Sperschneider, J., Dodds, P. N., Gardiner, D. M., Singh, K. B., and Taylor, J. M. 2018. Improved prediction of fungal effector proteins from secretomes with EffectorP 2.0. Mol. Plant Pathol. 19:2094-2110.

Yin, Y., Mao, X., Yang, J., Chen, X., Mao, F., and Xu, Y. 2012. dbCAN: A web resource for automated carbohydrate-active enzyme annotation. Nucleic Acids Res. 40:W445-W451.

Zerbino, D. R., and Birney, E. 2008. Velvet: Algorithms for $d$. novo short read assembly using de Bruijn graphs. Genome Res. 18:821-829.

\section{Author-Recommended Internet Resource}

RepeatMasker program: http://www.repeatmasker.org 